\title{
A New Specimen Geometry for Compression Hopkinson Bars
}

\author{
B. Deltort, A. Neme and B. Tanguy
}

Département Enseignement Recherche Mécanique (E.N.S.I.E.T.A.), 2 rue François Verny, 29806 Brest cedex 9, France

\begin{abstract}
Résumé. On s'intéresse ici à la caractérisation des matériaux aux barres d'Hopkinson de compression. Nous mettons tout d'abord en évidence, dans un cadre statique sur éprouvette classique (cylindrique), les perturbations engendrées par le frottement, le poinçonnement élastique ainsi que la flexion parasite. (On propose alors d'utiliser une nouvelle forme d'éprouvette. Des simulations numériques d'essais statiques sur ces dernières permettent d'identifier le comportement élastoplastique d'un acier (35NCD 16). Une première séric d'essais dynamiques avec cette même géométrie a été réalisée, puis analysée.
\end{abstract}

Abstract. This work is concerned with experimental characterization of materials with compression Hopkinson bars. First we point out the importance of friction, elastic punching and parasitic bending on the results of static compression tests with standard cylindrical specimens. Thus, we propose a new geometry for the sample, and then we conduct numerical simulations of the new steel sample ( $35 \mathrm{NDC} 16)$ under static loading to identify the constant parameters of its constitutive elastoplastic law. The early experiments with these specimens have been carried out and then analysed.

\section{INTRODUCTION}

This work is concerned with experimental methods for material characterization at high strain rates, and more particularly with compression Hopkinson bars. Although everyone agrees that the Hopkinson method is the easiest way to prescribe high strain rates in solids, more and more studies are conducted on the analyses of these kinds of tests as the means of obtaining the intrinsic constitutive law of the solid under consideration. The papers by A. Lichtenberger et al. [1], and H. Couque [2] are two examples. The former have pointed out the importance of friction on the results of dynamic compression tests. The latter has found that the strain state is not homogenous in the specimen.

We wish to emphasize these results. We carried out several static compression tests with a hydraulic press on steel cylindrical specimens $8 \mathrm{~mm}$ high and $7 \mathrm{~mm}$ in diameter. To press the samples, we used standard hardened steel compression anvils $40 \mathrm{~mm}$ high and $70 \mathrm{~mm}$ in diameter (figure 1). Three phenomena can be exhibited during this kind of test.
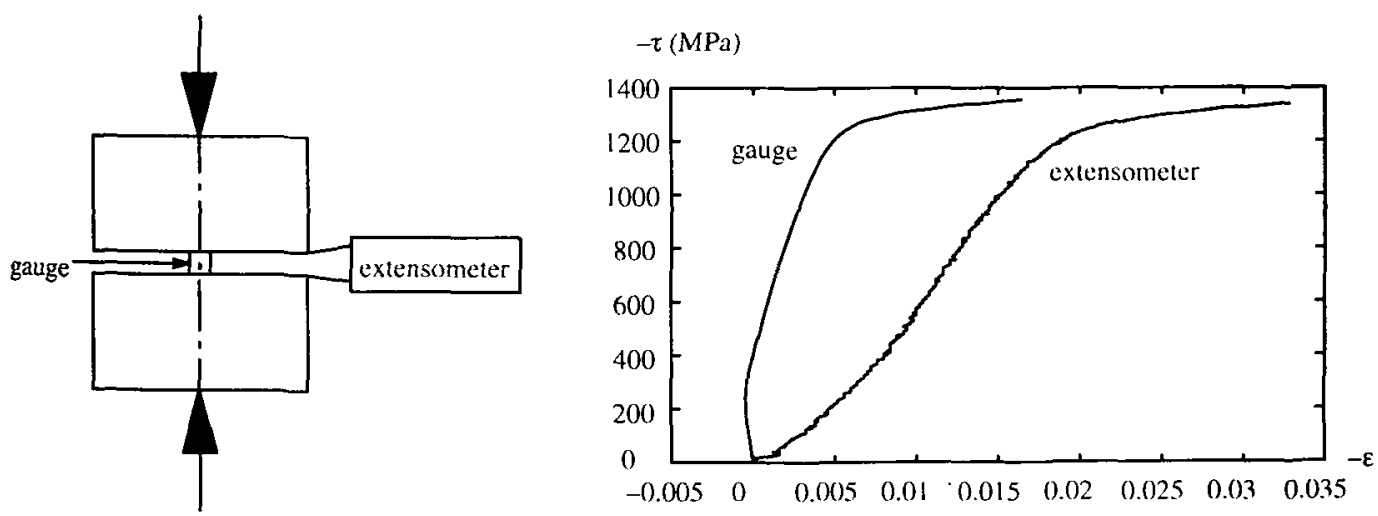

Figure I :Experimental means (left), minu. Kirhhoff stress sersus minus longitudinal logarithm strain (right)

Firstly, since the surfaces of the sample and those of the compression anvils are not exactly parallel, since the axis of the sample is not exactly the same as those of the compression anvils and since the piston of the 
press is not perfectly guided, bending occurs in the specimen. This phenomenon has been captured by meims of a gauge stuck on the sample (figure 1).

Secondly, the effects of both friction and elastic punching of the two compression anvils by the specimen lead to a state of heterogeneous strain in the sample which may even reach "barrel effect" for larts deformation. The punching effect can be observed on the figure 1. As a matter of fact. Young"s modulis: obtained with the extensometer $(88 \mathrm{GPa})$ is lower than those obtained with the gauge (206 GPa).

\section{NUMERICAL SIMULATION OF FRICTION EFFECTS}

The friction effects can be observed on the numerical simulations with ABAQUS/Standard 5.6 [3]. We used axisymmetric elements to mesh the sample and the compression anvils (figure 2). Only half of the struciure was meshed because of its axial symmetry. We considered an elastic behaviour with Young's modulus equil to $210 \mathrm{GPa}$ for the compression part, and an elastoplastic constitutive law with isotropic hardening for the specimen. Two kinds of Mises hardening law were tested. The first was linear (I) and the second logarithnic (2). All the values of the material parameters are given in table 1. A Coulomb friction model was used fir contact with three different values of the friction coefficient : $0,0.01,0.1$.

$$
\begin{gathered}
\bar{\sigma}=\sigma_{0}+K_{1} \bar{\varepsilon}_{\mathrm{p}} \\
\bar{\sigma}=\sigma_{0}+\mathrm{K}_{2} \ln \left(1+\mathrm{n} \bar{\varepsilon}_{\mathrm{p}}\right)
\end{gathered}
$$

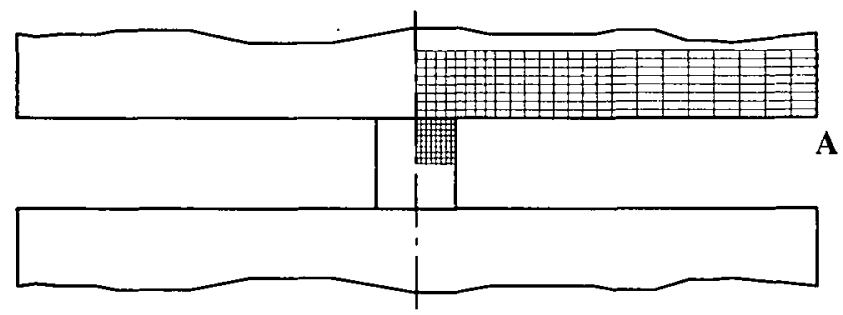

Figure 2: Mesh of the compression test

During computation, the axial displacement of point $\mathbf{A}$ was recorded. Thus, we were able to conduct the standard analysis of this numerical compression test as we did for the experimental one owing to the extensometer data. This standard analysis erase the friction and elastic punching effects because the underlying assumption is that there is no friction between sample and compression anvils, and that the contit surfaces are perfectly rigid. So, we have obviously obtained differences between the hardening law (1) or (2) and the hardening law obtained from the standard analysis. This is shown on figure8.

Table I: Material parameters

\begin{tabular}{|c|c|c|c|c|c|c|}
\hline Material & $\mathrm{E}(\mathrm{GPa})$ & $v$ & $\sigma_{0}(\mathrm{MPa})$ & $\mathrm{K}_{1}(\mathrm{MPa})$ & $\mathrm{K}_{2}(\mathrm{MPa})$ & $\mathrm{n}$ \\
\hline sample & 210 & 0.3 & 11.1 & 500 & 72.9 & $4110^{8}$ \\
\hline anvil & 210 & 0.3 & & & & \\
\hline
\end{tabular}

The friction and punching effects lead to both a state of heterogeneous strain and barrel shape for the sample. The higher the friction coefficient, the greater these effects (figure 9).

In order to avoid all these phenomena which are still present in compression Hopkinson tests, we propose a new geometry for the specimen. Before studying the dynamic case, we discuss the static case.

\section{COMPARISON BETWEEN THE STANDARD AND THE NEW SAMPLE UNDER STATIC COMPRESSION}

The new specimen geometry (figure 3) has been tested under static compression with the same compressitul anvils as explained in section 1 .. Nevertheless, we added an external tube (figure 4 ) to guide the piston of the 
engine, and thus the bending effects have been drastically reduced.

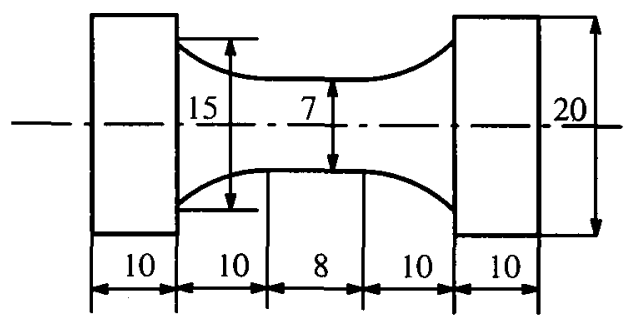

Figure 3 : New specimen geometry in $\mathrm{mm}$

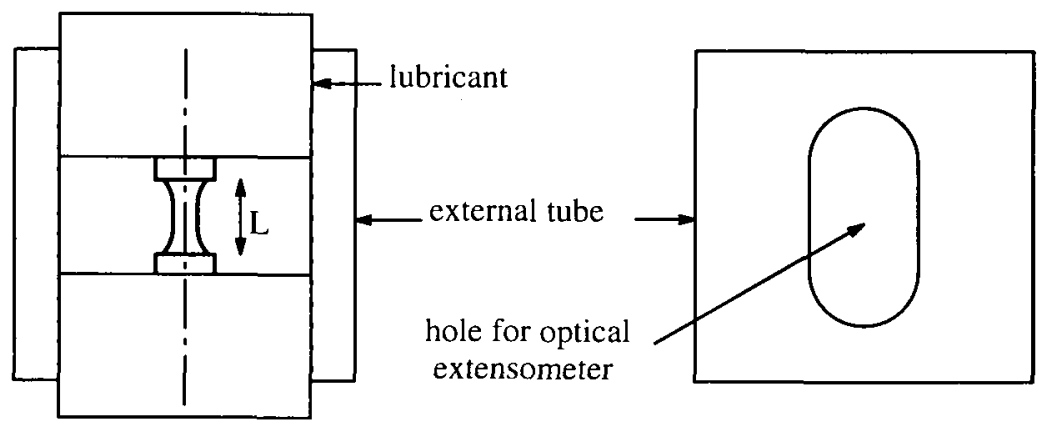

Figure 4 : Experimental set for static compression test on new specimen

An optical extensometer enables to record the distance $\mathrm{L}$ between the two opposite shoulders of the sample during the compression ( $\mathrm{L}$ initial value : $28 \mathrm{~mm}$ ). Then, an inverse method [4] has been used to determine the elastoplastic constitutive law of the steel (35NCD16). The experimental data retained to minimize the error between simulation and experiment is the curve taken from the compression strength versus $\mathrm{L}$ variation $\left(\mathrm{L}_{0}-\mathrm{L}\right.$ ). The result is the hardening law (2). As a proof of the good accuracy of the optimization, we can compare the numerical with experimental shape of the specimen after unloading (figures 10 and 5).

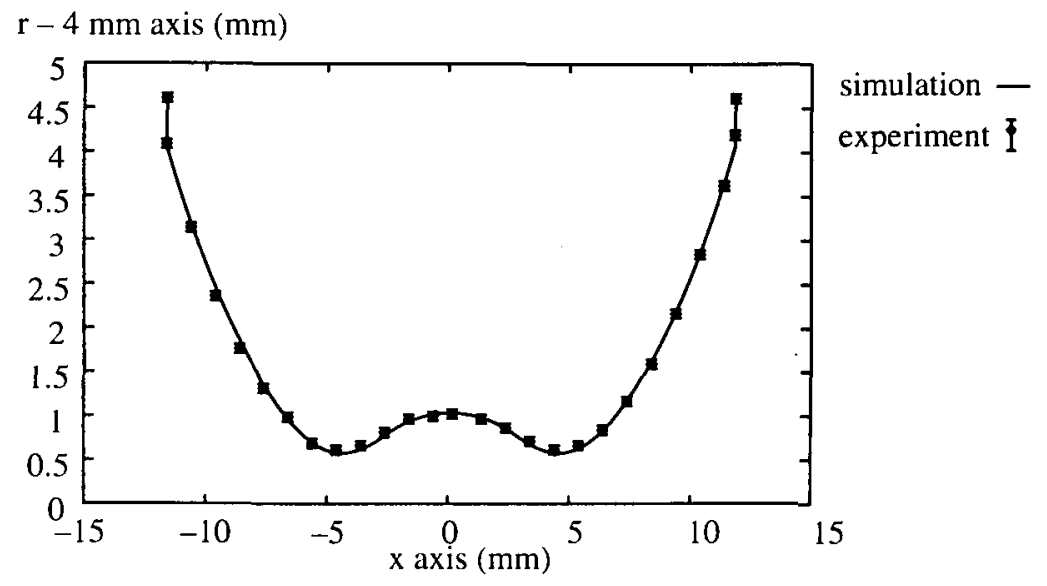

Figure 5 : Comparison between experimental and numerical profile of the sample after unloading

Now, it is possible to compare the optimal hardening law obtained from the compression test on the new specimen with the hardening law obtained by the standard analysis of the compression test on standard specimens. Although the two kinds of sample were nade of the same material. it is clear that the standard analysis gives wrong results due to the combined effects of bending. friction and punching (figure 6). 


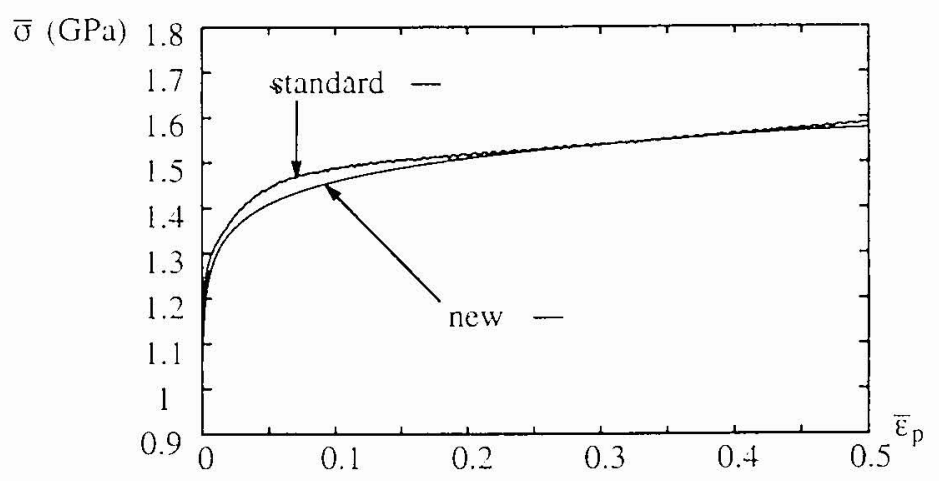

Figure $6:$ Comparison between hardening laws oblained with new and standard samples

\section{NEW SAMPLE UNDER DYNAMIC COMPRESSION}

Bearing these previous results in mind, we justify the choice of a new geometry for the sample used with compression Hopkinson pressure bars. As a matter of fact, the sample and the bars are equal in diameter: the contact surface location ( $A$ and $B$ figure 7 ), so the friction effects and the elastic punching of the bars ar: drastically reduced compared to those obtained with a standard cylindrical specimen.

Nevertheless, a new phenomenon appears with this new specimen. Indeed, the latter is more bucklin: sensitive than the old one since it is longer. We used two guide rings to avoid this buckling. The bending v? incident and transmitted bars were not eliminated, however, so that the sample did exhibit some bucklifis (figure 7).

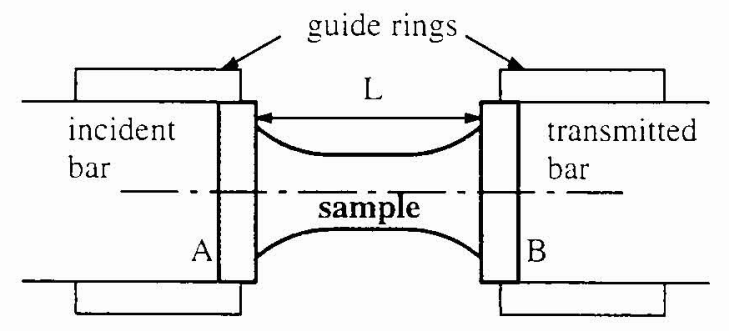

a)

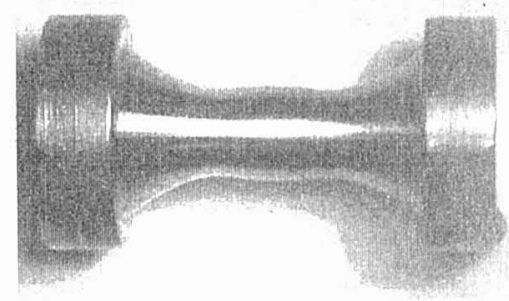

b)

Figure 7 : Experimental set for dynamic compression test on new specimen a), post-mortem sample after dynamic test b)

The early experimental results of dynamic compression tests on new specimens are shown on figure 11 As we did on static compression tests, we measured the $L$ variation (figure 7 ) by means of an opticit extensometer. The strength applied on the sample was classically determined by measuring the strain travelling through the incident and the transmitted bars. Figure 11, we plotted the strength versus $L$ variation for the static test and for two dynamic tests with different strain rates. Classic results can be observed. Firstly the higher the nominal strain rate, the higher nominal yield stress, for small strains. Secondly, for large strains the dynamic yield stress decreases with the nominal strain because of thermal softening.

\section{CONCLUSION}

The compression tests need serious analysis to obtain an accurate constitutive law. Although bending. friction and elastic punching lead to heterogeneous strain state in standard (cylindrical) samples, the whole effects generate an error on static yield stress less than about $2.5 \%$. Moreover, this result will have to be checked with other metals. Nevertheless, this can be important when considering bifurcation problems [5].

This study must be carried on especially for dynamic tests. The comparison between standard and new specimens in Hopkinson compression experiments is an ongoing work. Finally, we think the dynami experimental set can be improved by substituting a single guide ring pulled over the end of both incident and transmitted bars for the two original ones. 


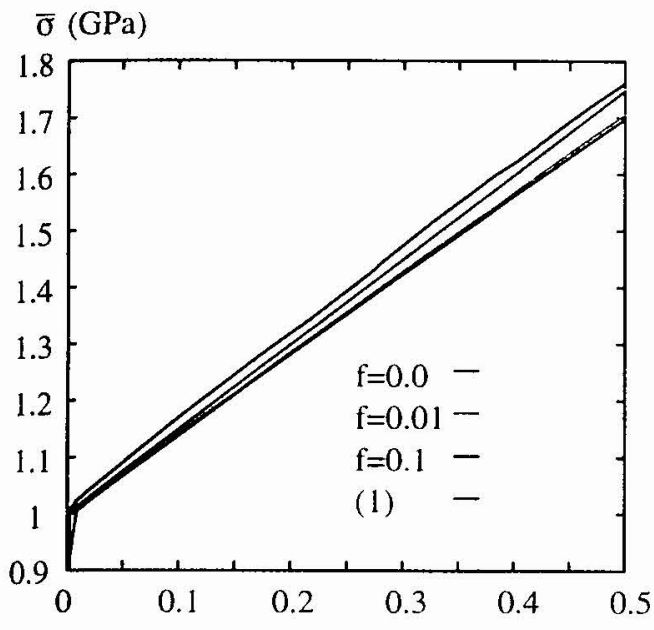

a)
$\bar{G}(\mathrm{GPa})$

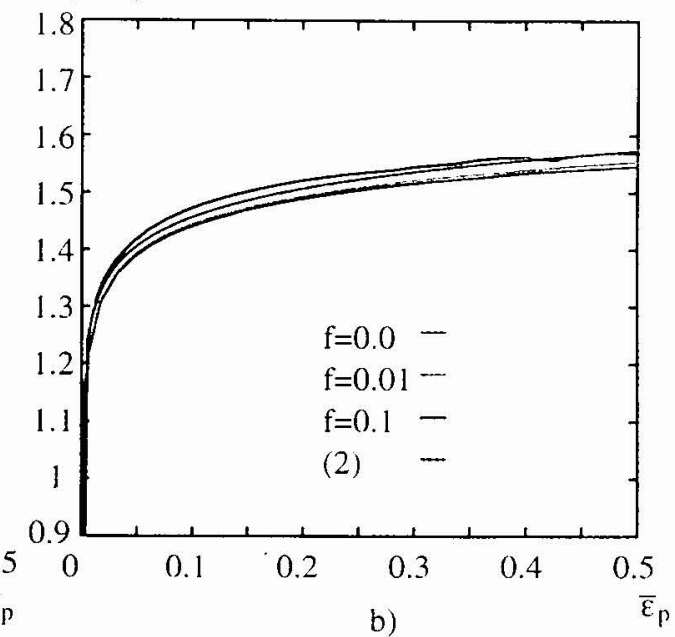

Figure 8: Comparison between hardening laws, friction (f) and elastic punching effects : a) equation (I), b) equation (2)
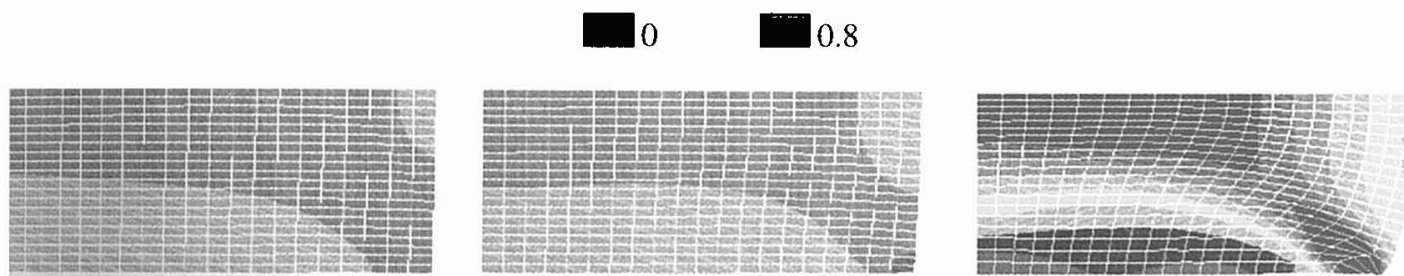

Figure 9: Mises equivalent plastic strain state in sample compressed up to half its initiallength using equation (2)

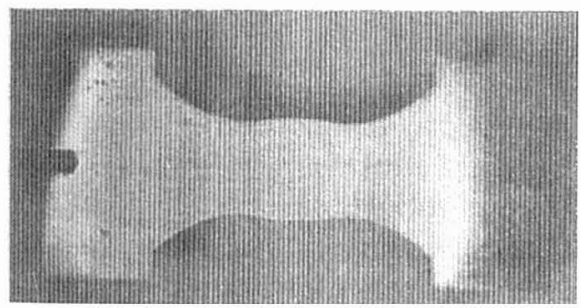

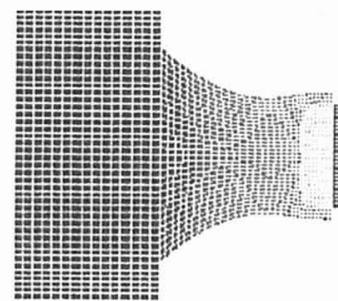

final shape and equivalent plastic strain

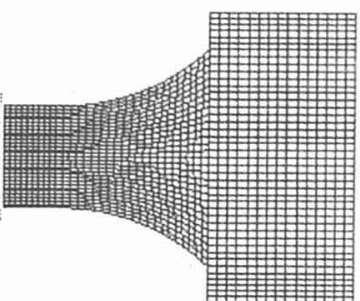

initial shape

Figure 10 : Experimental (left) and numerical (right) shape of the sample after unloading compression strength $(\mathrm{KN})$

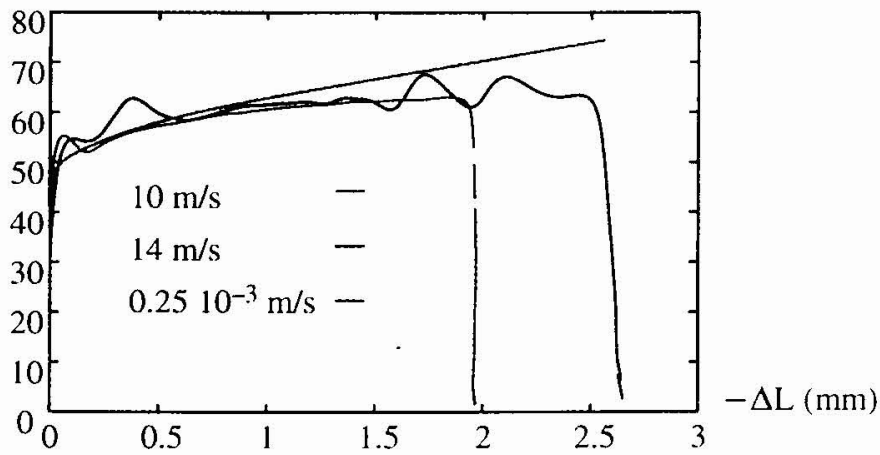

Figure 11 : Comparison between the static and two dynamic tests 


\section{Acknowledgements}

The authors wish to thank Raymond Le Prat for his invaluable assistance.

\section{References}

[1] A. LICHTENBERGER, E. LACH, A. BOHMANN : Analyse du frottement dans les essais de compression sur les barres d'Hopkinson, EURO DYMAT 94, Oxford, Sept 26-30, Journal de Physique IV, Colloque C8, supplément au journal de Physique III, Vol 4, p 29-34, 1994.

[2] H. COUQUE, J.D. WALKER : On the use of the compression split Hopkinson pressure bar to high strain rate, EURO DYMAT 94, Oxford, Sept 26-30, Journal de Physique IV, Colloque C8, supplément au journal de Physique III, Vol 4, p 23-28, 1994.

[3] HIBBITT, KARLSSON, SORENSEN, INC. : ABAQUS User's Manual 5.6., 1997.

[4] B. DELTORT, Identification of the thermo-mechanical behaviour of a martensitic steel under dynamic and static conditions, ACAM-96, Melbourne, Feb 21-23, Proc of the Australian Congress on Applied Mechanics, 1996.

[5] A. NEME, N. DAHAN, Analysis of the perforation of elastoplastic plates with bifurcation theory, DYMAT Journal, Vol. 2, n² 2 , p. 87-103, 1995. 